\title{
ASPECTOS DA BIOLOGIA DA REPRODUÇÃO EM PLANTAS ORNAMENTAIS CULTIVADAS NO ESTADO DE SÃO PAULO. I - DICHORISANDRA THYRSIFLORA MIKAN (COMMELINACEAE)
}

\author{
Yone M.S. Boaventura ${ }^{1,3}$ \\ Luiz A.F. Matthes 2.3
}

Recebido em 30.01.1987. Aceito em 17.11.1987.

\begin{abstract}
RESUMO - Foram estudados os possíveis sistemas de reprodução em Dichorisandra thyrsiflora. A espécie parece ser predominantemente de fecundação cruzada, embora sem um sistema de autoincompatibilidade definido. Conseqüentemente a autofecundação ocorre numa frequência bem menor. Quanto à agamospermia, nenhum fruto foi observado em flores não polinizadas. Os agentes polinizadores, invariavelmente, são insetos do gênero Bombus. Observou-se que o número cromossômico da espécie é $2 \mathrm{n}=38$. A análise da microsporogénese mostrou que a meiose é normal com exceção de algumas células mães de pólen nas quais foi observada a formação de pontes cromatínicas em anáfases I e II, sugerindo existência na população de heterozigotos para inversão. A formação de tétrades normais foi de $95 \%$ e a viabilidade dos grãos de pólen foi alta, $87,2 \%$.
\end{abstract}

Palavras-chaves: Plantas Ornamentais-Biologia da Reprodução, Dichorisandra thyrsiflora-Commelinaceae, Microsporogênese.

\begin{abstract}
Aspects of breeding system of Dichorisancha thyrsiflora Mikan.) The breeding system of Dichorisandra thyrsiflora was studied. It was found that this is a mainly cross- pollinated species $(92 \%)$, without a well defined self-incompatibility mechanism. Self-pollination was obtained in $27 \%$ of the analysed flowers, and apomixis was not observed. Pollination agents were mainly of the Bombus genus. The chromosome number of the species was $2 \mathrm{n}=38$. Microsporogenesis analysis showed normal meiosis, with only a few exceptions, in which chromatic bridges formation was observed in the anaphase $I$ and II, suggesting heterozygosity for the inversion. Normal tetrad formation was $95 \%$ and pollen viability was high $(87,2 \%)$.
\end{abstract}

Key words: Dichorisandra thyrsiflora-Commelinaceae, Microsporogenesis-breeding system.

\footnotetext{
${ }^{1}$ Secção de Citologia, Instituto Agronômico, Caixa Postal 28, 13.020 - Campinas, Brasil.

${ }^{2}$ Seção de Floricultura e Plantas Ornamentais.

${ }^{3}$ Bolsista do CNPq.
} 


\section{Introdução}

A exploração comercial de plantas ornamentais em nosso país tem se expandido muito nos últimos 15 anos, passando de uma atividade amadorística a verdadeiras empresas comerciais, principalmente no estado de São Paulo.

$\mathrm{O}$ Brasil possui uma flora riquíssima e em relação a muitas espécies que possuem características ornamentais, não se conhecem sequer os aspectos básicos, principalmente, aqueles relacionados à reprodução. Tais informações além de contribuir para o conhecimento de nossa flora, deverão propiciar a realização de cruzamentos melhor dirigidos em trabalhos de melhoramento genético, imprescindíveis à obtenção de material comercialmente viável.

Com o objetivo de estudar esses aspectos básicos da reprodução sexuada, as Seções de Citologia e de Floricultura e Plantas Ornamentais do Instituto Agronômico de Campinas, vêm realizando pesquisas com diversas espécies vegetais. Entre estas, encontra-se a Dichorisandra thyrsiflora (Trapoeraba azul). Esta espécie é uma Commelinaceae comumente cultivada nos jardins brasileiros e de outros países, devido ao valor ornamental de sua folhagem e da cor de suas flores azul-metálicas.

A espécie é citada como nativa do Estado do Rio de Janeiro, Brasil, na Flora Brasiliensis (SEUBERT, 1855), com a época de floração de dezembro a fim de fevereiro.

\section{Material e métodos}

Os indivíduos estudados encontram-se em cultivo no parque do Instituto Agronômico de Campinas, São Paulo, com procedência desconhecida, portanto, fora de seu habitat natural. Este material foi herborizado e introduzido no Herbário do Instituto Agronômico sob o número IAC-25.597.

$\mathrm{O}$ período de observação das inflorescências, visando a análise do sistema de reprodução, foi de 6 de abril a 29 de junho de 1981, coincidindo assim com o período de floração desta espécie nas condições de cultivo, diferente da época de floração no seu habitat natural. Foram feitas observações em 137 flores de 29 inflorescências pertencentes a 10 indivíduos diferentes.

Inicialmente foram feitas observações sobre a biologia floral, isto é, como e quando as flores se abriam e quais os insetos visitantes.

Nas flores foram realizadas autopolinizações, polinizações cruzadas, além de alguns botões terem sido emasculados para verificar se haveria agamospermia. Além desses, um total de 60 flores foram marcadas, 30 que apresentavam estilete longo e 30 com estilete curto em várias inflorescências de diferentes indivíduos. Essas flores foram deixadas à livre polinização e deveriam servir como controle sobre o que seria afetado pelos danos de manipulação.

As emasculações foram realizadas logo após a abertura das flores, pois, foi verificado que a antera, que é poricida, nesta fase ainda não liberou os grãos de pólen.

As inflorescências utilizadas para todos os tratamentos foram ensacadas antes e após os tratamentos. 
A análise citológica para a determinação do número de cromossomos foi realizada em pontas de raízes oriundas de 10 sementes. Para o comportamento meiótico na microsporogênese e viabilidade do pólen, botões jovens de 5 plantas foram fixados desde a fase pré-meiótica até a antese da flor.

I. MITOSE - As pontas de raízes foram pré-tratadas em paradiclorobenzeno (PDB) por 6 horas à temperatura de 16 a $18^{\circ} \mathrm{C}$. A seguir, o material foi fixado em Carnoy 1:1. A coloração utilizada foi a reação nuclear de Feulgen (LISON, 1960); as pontas de raízes coloridas foram preparadas pelo sistema de esmagamento em ácido acético $45 \%$ e depois seladas. Foram examinadas 10 preparações que corresponderam às 10 raízes.

II. MEIOSE - Para as observaçōes na microsporogênese os botōes foram dissecados e fixados em Carnoy 3:1, o fixador foi renovado por três vezes num período de 48 horas. O material foi resfriado e guardado em congelador, à temperatura aproximada de $-20^{\circ} \mathrm{C}$, no próprio fixador até o momento do preparo das lâminas. Para a preparação das lâminas foi usado carmim propiônico (MEDINA e CONAGIN, 1964).

Através da contagem de quiasmas em 50 células em diacinese e $50 \mathrm{em}$ metáfase I, foi determinado o índice de recombinação (IR) para cada uma destas fases, segundo a fórmula de DARLINGTON (1958).

Como as inflorescências apresentan flores de dois tipos, com estilete longo e curto, tanto para a análise das tétrades de micrósporos como para a da viabilidade do pólen, foram utilizadas três flores de cada tipo para verificar se havia ou não diferença na fertilidade das mesmas. Também as anteras de uma mesma flor, por apresentarem tamanho e morfologia diferenciadas, foram analisadas separadamente.

As observações dos grãos de pólen foram feitas em 12 preparações com carmim propiônico, cada duas representando uma flor. Foi utilizado sempre pólen maduro, coletado no dia da antese, de flores previamente protegidas.

Ovários de flores com estilete curto e longo foram cortados transversalmente, depois de fixados em Craf, incluídos em parafina e coloridos com hematoxilina férrica (MEDINA e CONAGIN, 1964), para verificar se ambos eram igualmente normais.

As células em diferentes fases de divisão tanto de raiz como das células mães de pólen foram observadas, interpretadas e fotografadas.

\section{Resuitados}

\section{Biologia floral}

Dichorisandra thysiflora Mikan é uma planta herbácea, com folhas em espiral e caule articulado. A inflorescência é uma panícula tirsoídea. A flor, actinomorfa, tem coloração intensa que varia de rosa ao azul-metálico e duração de um dia; é hermafrodita e possui 6 estames ( 4 menores e 2 maiores), com anteras de poro apical; o ovário é supero, tricarpelar, trilocular, com 6 óvulos рог loja. O estilete é branco, localizando-se no centro das 4 anteras menores. 
Foram observadas duas formas florais ocorrendo dentro da mesma inflorescência: uma com estilete longo, cujo comprimento era superior ao das anteras, ficando assim com o estigma exposto, a outra com estilete curto, localizado abaixo do nível das anteras, sem exposição do estigma. Os frutos são cápsulas deiscentes, carnosas e as sementes são pretas envolvidas por arilo branco.

Em 10 inflorescências de $D$. thyrsiflora analisadas ao acaso foi observada uma grande variação no número de botôes florais, de 40 a 112, dentro e entre cerca de 10 indivíduos.

Nas primeiras horas do dia $(6: 00$ às $8: 00 \mathrm{~h})$ ocorre a antese. Logo a seguir o estilete, que se apresentava na posição vertical durante a antese, curva-se num ângulo de aproximadamente 90 graus. Somente a partir das 9:00 horas o pólen é liberado das anteras.

Foi observada a ocorrência de uma espécie de mamangava, abelhas, pertencente ao gênero Bombus, visitando flores de D. thyrsiflora. As mamangavas prendem o cone de anteras com suas patas e mandíbulas e, através de vibração, liberam o pólen do interior da antera em questão de segundos. Com a vibração todo o corpo do inseto fica impregnado com pólen que mais tarde é armazenado em suas corbículas.

A visita desses polinizadores mostrou uma freqüência maior durante o período da manhã, tornando-se mais raras no período da tarde.

\section{Reprodução}

Os resultados sobre a polinização natural e a polinização controlada dos diversos tratamentos efetuados como autopolinização, polinização cruzada e agamospermia, bem como a separação em flores com estilete longo e flores com estilete curto estão apresentados na Tabela 1 .

Para as flores com estilete longo foram observados resultados positivos e negativos e para as de estilete curto, só eventos com resultados negativos.

TABELA 1 - Formação de frutos de $D$. thyrsiflora nos diferentes tratamentos.

\begin{tabular}{lrrrrrrrrrrrrr}
\hline & \multicolumn{3}{c}{$\begin{array}{c}\text { Polinização } \\
\text { aberta }\end{array}$} & \multicolumn{3}{c}{$\begin{array}{c}\text { Auto- } \\
\text { polinização }\end{array}$} & \multicolumn{3}{c}{$\begin{array}{c}\text { Polinização } \\
\text { cruzada }\end{array}$} & \multicolumn{3}{c}{ Agamospermia } \\
& $(-)^{*}$ & $(+)$ & $N^{\circ}$ & $(-)$ & $(+)$ & $N^{\circ}$ & $(-)$ & $(+)$ & $N^{\circ}$ & $(-)$ & $(+)$ & $N^{\circ}$ \\
\hline Flor com estilete longo & 8 & 22 & 30 & 16 & 6 & 22 & 1 & 11 & 12 & 11 & 0 & 11 \\
Flor com estilete curto & 30 & 0 & 30 & 6 & 0 & 6 & 56 & 0 & 56 & 30 & 0 & 30 \\
\hline Total de flores & & & 60 & & 28 & & 68 & & 41 \\
\hline
\end{tabular}

${ }^{*}$ Sinal (-) significa a não formação de frutos e o sinal (+) a formação de grutos.

Foi possível constatar que as flores de estilete curto que foram deixadas a livre polinização, isto é, aberta não produziram frutos e nas flores de estilete longo frutificaram $22(73 \%)$. 
Parece não ocorrer agamospermia na espécie. Os resultados foram todos nulos, quando não houve polinização.

Nas flores de estilete longo, as únicas nos tratamentos que formaram frutos, foi verificado que nas autopolinizadas $27,3 \%$ frutificaram, enquanto que nos cruzamentos foi obido $91,7 \%$ de frutos.

Quanto ao número de sementes formadas por fruto (18 óvulos) observou-se uma relação média de 15 sementes $(83,3 \%)$ nas polinizações naturais, $26,7 \%$ nas autopolinizações e $36,1 \%$ nas polinizações cruzadas.

\section{Citologia}

Em mitose, o número encontrado em todas as células analisadas foi de $2 n=38$ cromossomos. A espécie possibilita boas preparações citológicas de pontas de raiz primária, células com citoplasma claro e cromossomos bem espalhados com 6 horas de paradiclorobenzeno, permitindo um estudo de caracterização cromossômica pelo tamanho e pela forma dos mesmos e pela distinção da região centromérica. Os 19 pares homólogos decrescem gradualmente de tamanho, não possibilitando neste aspecto qualquer reconhecimeto de grupos. (Fig. 1).

Sobre o comportamento meiótico de $D$. thyrsiflora foi possível confirmar um número estável de cromossomos nas células mães de pólen de 19 bivalentes, em todas as fases da microsporogênese observadas.

As fases iniciais da prófase meiótica foram difíceis de interpretar.

Em fase de diacinese, os cromossomos se apresentam sempre na forma de bivalentes com um, dois e três quiasmas. Muito raramente foram observados cromossomos não pareados, na forma de monovalentes.

$\mathrm{Na}$ maioria dos bivalentes em diacinese, os quiasmas se localizam na região distal dos cromossomos, longe dos centrômeros, em ambos os braços, dando-lhes uma aparência fechada, semelhante à um anel. Em alguns casos entretanto, os quiasmas estão localizados de forma assimétrica, só em um dos braços; estes bivalentes se apresentam em forma de V, mais ou menos aberto (Fig. 2). Na tabela 2 estão reunidas as observações sobre o número de quiasmas nesta fase, num total de 50 células analisadas. Em média, cada célula apresentou cerca de dois bivalentes $(1,70)$ com apenas um quiasma; cerca de $16(15,92)$ com dois quiasmas por bivalente e cerca de um par $(1,30)$ com três quiasmas, produzindo um total médio de quiasmas por célula de 37,44. O índice de recombinação encontrado foi de 56,44 .

As mesmas observações foram feitas em 50 células em metáfase I, dando resultados um pouco diferentes dos obtidos em diacinese, como seria esperado. $\mathrm{O}$ número de bivalentes com um, dois e três quiasmas foi respectivamente 4,$40 ; 13,98$ e 0,54 o que dá um total de 33,98 quiasmas por célula (Tabela 3). $O$ índice de recombinação encontrado foi de 52,98 . 
TABELA 2 - Número de quiasmas e sua distribuição pelos bivalentes em 50 células em diacinese de $D$. thyrsiflora.

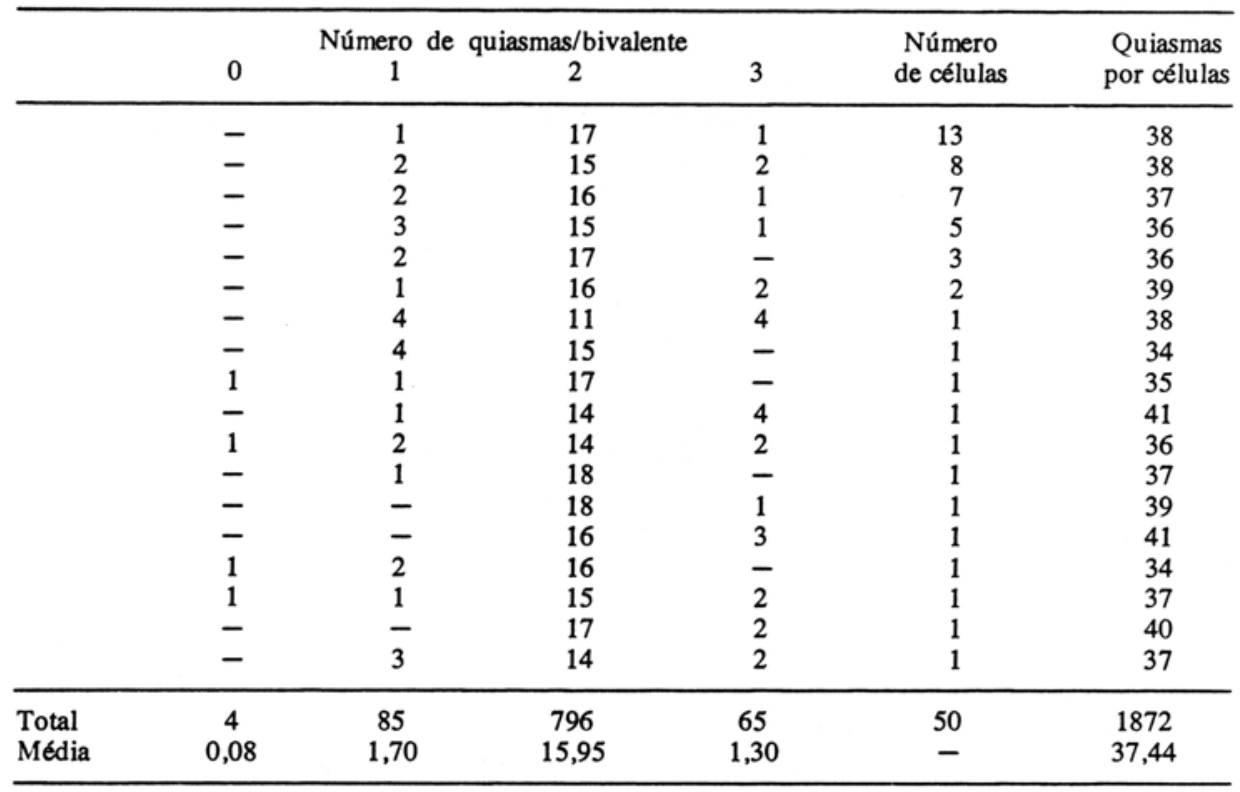

TABELA 3 - Número de quiasmas e sua distribuição pelos bivalentes em 50 células em metáfase I de D. thyrsiflora.

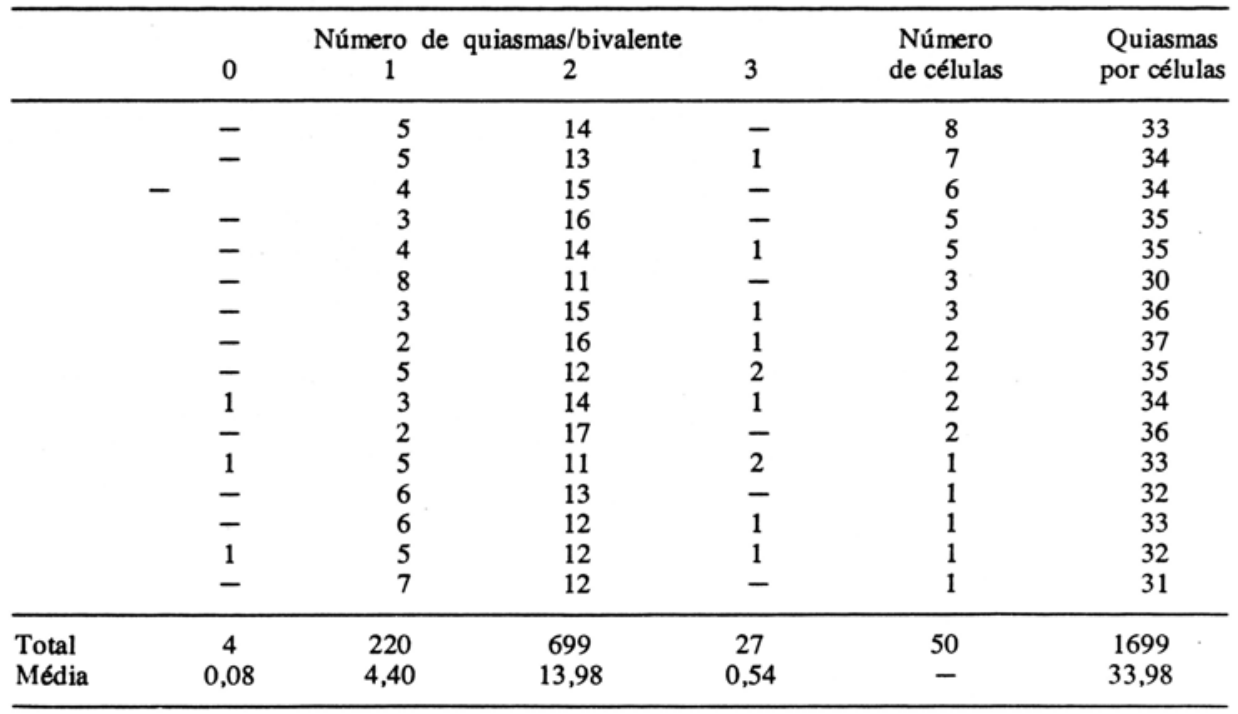


Em anáfase I, de 106 células analisadas, 85,9\% apresentaram uma disjunção normal para os pólos de $19-19$ cromossomos (Fig. 3). As irregularidades anafásicas se resumem praticamente na formação de pontes cromatínicas; em $12,3 \%$ das células foi observada a formação de uma ponte (Fig. 4) e em 1,9\% duas pontes por célula. Cromossomos retardatários e disjunções irregulares não foram notados seja em $\mathrm{A}_{\mathrm{I}}$ ou $\mathrm{A}_{\mathrm{II}}$.

O mesmo ocorreu em anáfase II onde $89,2 \%$ das 83 células analisadas apresentaram uma distribuição normal de 19 cromossomos para cada um dos quatro pólos. Em 10,8\% das células foram observadas pontes cromatínicas que sugerem a existência de heterozigotos para inversão (Fig. 5).

Após a ocorrência da citocinese foram observadas 500 células onde foram encontradas tríades de micrósporos $(1,0 \%)$, tétrades normais $(95,0 \%)$, tríades com um micrócito $(3,0 \%)$ e díades com dois mirócitos $(1,0 \%)$. A viabilidade dos grãos de pólen encontrada em 500 contagens, em média, foi de 87,2\% tanto nas flores que apresentaram estilete longo como nas de curto, bem como nas duas anteras maiores e nas quatro menores. A análise revelou serem todas igualmente férteis.

Em cortes transversais de ovários, coletados no dia da abertura da flor, nos dois tipos de flores foi observado que somente nas flores de estilete longo os óvulos eram normais, nas de estilete curto os óvulos não se formavam. Nas flores de estilete curto, foi observado, somente uma leve diferenciação celular no tecido do ovário nas regiões de formação dos sacos embrionários.

\section{Discussão}

De acordo com os resultados obtidos na Tabela 1 para as flores de estilete longo, apesar do pequeno número de flores analisadas, observa-se em Dichorisandra thyrsiflora um maior sucesso com as polinizações cruzadas do que com as autopolinizações realizadas.

Em 12 cruzamentos entre plantas, somente em um não houve a formação de frutos enquanto que em 22 autopolinizações, 16 não formaram frutos.

A falta de formação de frutos na polinização cruzada pode ser explicada por ialta técnica nas polinizações manuais, ou ainda, alternativamente, o estímulo mecânico de polinização por insetos para formação do tubo polínico pode ser diferente do estímulo da polinização normal. Causas de ambiente não devem ser desprezadas. Por outro lado, o baixo pegamento dos frutos nas flores autofecundadas, parece ser mais provável, poderia também ser explicada por mecanismos incipientes de autoincompatibilidade. Neste caso, torna-se difícil saber qual dos mecanismos estaria envolvido, se gametofítico ou esporofítico, sendo que no gametofítico, segundo BREWBAKER (1969), a incompatibilidade ocorreria principalmente em plantas com pólen binucleado. Isto realmente ocorre nos grãos de pólen de Dichorisandra, que são binucleados. Porém, outros estudos devem ser realizados para se chegar a uma conclusão mais definitiva, como por exemplo, estudos nos tubos polínicos de grãos germinados em estigmas da própria planta e o prosseguimento dos mesmos até a fertilização da oosfera. 
Para as flores que apresentaram estilete em tamanho reduzido observou-se que não houve a formação de um fruto sequer, sendo o fato compreensível, pois, os óvulos dessas flores são geralmente abortivos, pois, não são formados sacos embrionários, mesmo para aqueles em que o estilete se encontra perfeito, somente com comprimento menor. Essas flores, que ocorrem de maneira aleatória em posição e tempo na inflorescência, funcionam só como flores masculinas já que não foi observada nenhuma diferença na formação dos grãos de pólen destas em relação às flores normais.

De acordo com os resultados, nenhum caso de agamospermia foi observado.

Durante as visitas do agente polinizador, observou-se que o Bombus sp., segurava todas as anteras de uma só vez e promovia um movimento de vibração para a retirada de pólen. Ao fazer tal operação, o provável de ocorrer, já que não foi observado, é que o estilete, estando numa posição de $90^{\circ}$, toque regiões do abdomem, patas e até mesmo a massa de pólen da corbícula, promovendo a transferência do pólen aderiḑo ao animal para o estigma, ocorrendo dessa maneira a polinização.

Cada ovário possui 18 óvulos e, portanto, seria esperado um número equivalente de sementes em cada fruto. Entretanto, foram observadas as porcentagens médias de $26,7 \%$ e $36,1 \%$ de sementes nos tratamentos autopolinização e polinização cruzada, respectivamente. Comparando os valores encontrados nestes dois tratamentos com a obtida por polinização natural $(83,3 \%)$, nota-se que esta última tem uma formação de sementes bem maior, o que pode ser devido a diferentes causas: a) não houve uma adequada polinização nos tratamentos artificiais - ou pólen escasso, ou pólen em excesso mas não devidamente colocado na superfície estigmática; b) o horário das realizações das polinizações não ter sido o adequado; c) algum tipo de reação do pólen com a pinça, com a qual se faziam as transferências do pólen das anteras para os estigmas; d) o estigma não estar receptivo ou o pólen não estar "maduro".

Em relação à análise citológica, tanto em mitose como em meiose, verificou-se que a espécie possui $2 \mathrm{n}=38$ cromossomos, concordando com os resultados apresentados por DARLINGTON (1929) e ANDERSON (1936) apud BOLKHOVSKIKH et al. (1969). Outras espécies como D. hexandra (Aubl.) Standley, D. reginae (L. Linden \& Rodigas) W. Ludw. e Dichorisandra sp. são citadas como tendo também $2 \mathrm{n}=28$ cromossomos, mas uma outra espécie ainda indeterminada é um tetraplóide segundo JONES \& JOPLING (1972) com 2n = 76 $+2 \mathrm{~B}$.

FUJISHIMA (1971) também encontrou $2 \mathrm{n}=38$ cromossomos para $D$. thyrsiflora. Este autor analisou o cariótipo e concluiu que o mesmo era constituído por 3 grupos de cromossomos segundo a posiçăo do centrômero: um grupo A com apenas um cromossomo metacêntrico, um grupo B de 9 cromossomos submetacêntricos e um grupo $\mathrm{C}$ com 9 cromossomos com centrômeros terminais.

$\mathrm{O}$ número básico $(\mathrm{x}=19)$ é um dos mais altos observados para a família, sendo que $x$ varia na família de 4 a 20 , com exceção de $x=18$ que não foi observado (JONES \& JOPLING, 1972).

Comparando-se os dados obtidos de quiasmas em diacinese em metáfase I (Tabelas 2 e 3), vê-se que como é esperado, que há terminalização nesta fase, e como conseqüência, uma alteração nas médias das classes de bivalentes 
com um, dois e três quiasmas: a classe de bivalentes com dois e três quiasmas diminui com a passagem do estado de diacinese para metáfase I, em conseqüência, a de bivalentes com um quiasma é aumentada. O índice de recombinação encontrado para $D$. tryrsiflora em diacinese e metáfase I foi de 56,44 e 52,98 , respectivamente. Essa diferença é esperada, pois, há uma terminalização de quiasmas na passagem de diacinese para metáfase $\mathrm{I}$.

$\mathrm{O}$ significado do valor encontrado para o índice de recombinação (IR) para a espécie, relacionando-o com o sistema de cruzamento, só poderá ser interpretado em comparação com os valores de IR de outras espécies do mesmo gênero e de mesmo número cromossômico; no nosso caso não foram encontrados outros valores para se fazer uma comparação. Dichorisandra é planta perene e segundo STEBBINS (1950), em plantas anuais a correlação esperada seria uma mais alta freqüência de quiasmas em plantas com autofecundação. De qualquer modo sendo $D$. thyrsiflora planta com predomínio de fecundação cruzada e número de cromossomos alto, provavelmente um poliplóide, esse número não pode ser considerado baixo.

A população deve compreender algumas plantas heterozigotas para inversão cromossômica. Essa inversão deve ser pequena, desde que somente vez por outra foram observadas pontes cromatínicas e segmentos em $A_{I}$ e $A_{\text {II }}$ numa freqüência de $14,4 \%$ e $10,8 \%$ das células. Os segmentos com dois centrômeros não foram vistos porque a espiralização dos cromossomos em Dichorisandra é sempre muito acentuada. A região invertida deve ser pequena, o que pode ter originado muitas vezes um pareamento normal, sem formação de alça, isto é, falta de pareamento na região invertida ou falta de permutação no segmento invertido. Em conseqüência disso, foi constatado alta freqüência de tétrades e pólen viável (Fig. 6).

\section{Conclusões}

- Em relação ao sistema de reprodução, apesar do baixo número de flores analisadas, pode-se afirmar que a espécie é predominantemente de fecundação cruzada. A autofecundação também ocorre, embora tenha sido observada em uma porcentagem menor. Quanto a agamospermia, não foi observada nos experimentos aqui realizados.

- Os agentes polinizadores, que promovem a fecundação cruzada, são abelhas do gênero Bombus.

- O número de cromossomos é $2 \mathrm{n}=38$.

- A meiose nos indivíduos ocorreu de maneira normal, com exceção de alguns casos com formação de pontes sugerindo heterozigose para inversão.

- A formação de tétrades de mirósporos foi normal em $95 \%$ dos casos.

- A viabilidade dos grãos de pólen foi de $87,2 \%$, indicando que as plantas estudadas são férteis. 

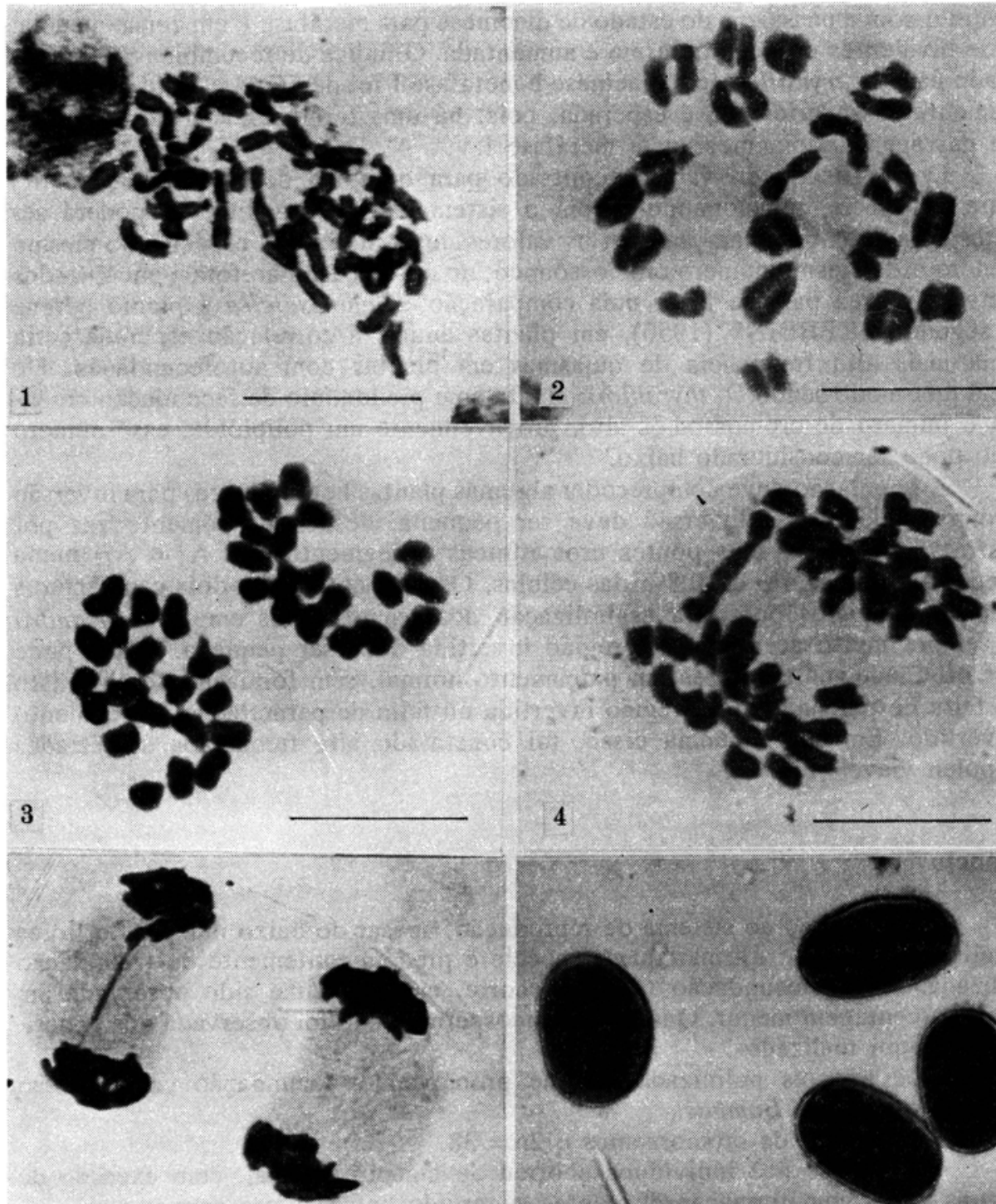

5

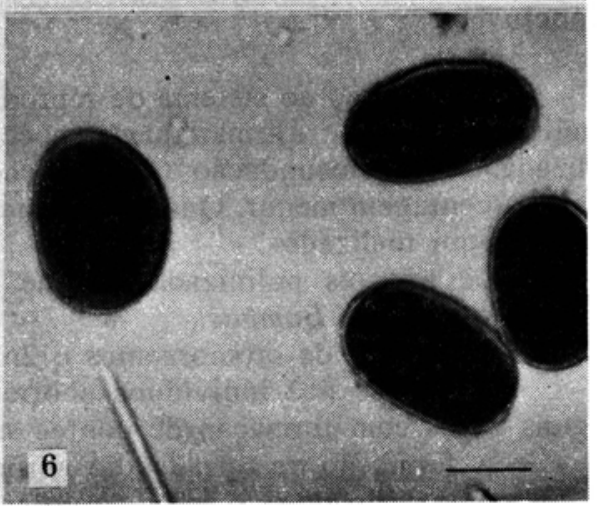

FIGURA 1 - Metáfase mitrtica em raiz, mostrando 38 cromossomos. FIGURAS 2 A 6 Microsporogênese em Dichorisandra thyrsiflora. 2 - Diacinese, cromossomos com um e dois quiasmas. 3 - Anáfase I com separação normal de $19-19$ cromossomos. 4 - Anáfase I com ponte de cromatina. 5 - Anáfase II com ponte. 6 - Campo mostrando pólen normal binucleado. (Escala $=2$ um). 


\section{Referências Bibliográficas}

BOLKHOVSKIKH, Z.; V. GRIF; T. MATVEJEVA \& O. ZAKHARYENA. 1969. In: FEDOROV, An. A., ed Chromosome Number of Flowering Plants. V.L. Komarov Botanical Institute, Academy of Sciences of the U.S.S.R.

BREWBAKER, J.L. 1969. Genética na Agricultura; tradução de J.T. do Amaral Gurgel e Roland Vencovsky. S. Paulo, Polígono e ed. da U.S.P. 224p.

DARLINGTON, C.D. 1958. The Evolution of Genetics Systems. Basic Books, INC. Publishers. New York. 265p.

FUJISHIMA, H. 1971. Karyological studies in Commelinaceae: IV - Karyotypes of the genus Tradescantia (tropical species) and the some species in affinitive genera. La Kromosomo, 85/86: 2713-2727.

JONES, K. \& C. JOPLING. 1972. Chromosomes and ciassification of Commelinaceae. Bot. j. linn. soc., 65: 129-162.

LISON, L. 1960. Histochimie et Cytochimie Animales. Principes et Méthodes. Collection des Actualités Biologiques. GAUTHIER VILLARS, ed. Paris. $397 \mathrm{p}$.

MEDINA, D.M. \& C.H.T.M. CONAGIN. 1964. Técnica Citológica. Instituto Agronômico. Campinas, São Paulo. Publicação n. 2610. 108p.

SEUBERT, M. 1855. Xyrideae, Mayaceae et Commelinaceae in Martius Flora Brasiliensis, III (1): 209-270.

STEBBiNS, G.L. 1950. Variations and Evolution in Plants. Columbia University Press, New York. 646pp. 